\title{
An Objective Measure of Gait USING INK FOOTPRINTS
}

\begin{abstract}
A study was conducted to test the usefulness of seven temporal distance measurements (measurements of time and distance) in the assessment of functional ambulation in stroke patients. These measurements were obtained simply and inexpensively using a paper walkway and ink footprints.

The gait of ten hemiparetic patients was initially assessed according to the Massachusetts Functional Ambulation Rating. Each patient was then instructed to walk at his/her most comfortable speed along a ten metre paper walkway while velocity and cadence were measured. Ink
\end{abstract}

\begin{tabular}{|l|}
\hline RILEY M, MCSP, MSC (WITS) \\
GOODMAN M, PHD (WITS) \\
FRITZ VU, MB BCH, FCP (SA), PHD (MED) \\
I Postgraduate student, University of the Witwotersrand, \\
Johonnesburg \\
2 Department of Physiotherapy, University of the Witwatersrand, \\
Johannesburg \\
3 Department of Neurology, Universily of the Witwatersrand, \\
Jahannesburg
\end{tabular}
pads were then attached to the heel and toe of each shoe and the patients walked again along the walkway. Measurements of step length, stride length, stride length: lower extremity length ratio, foot angle and width of base were recorded and analysed.

Velocity and cadence were found to correlate well with the functional ambulation rating. Step length was found to correlate with the functional ambulation rating, but the longer step was not always taken with the affected leg. Stride length and stride length : lower extremity length ratio correlated well with the functional ambulation rating. Foot angle and width of base did not correlate with function but all hemiparetic patients showed a greater foot angle with the affected leg.

This method of data collection is inexpensive and easy to use in any physiotherapy department although the data analysis is time-consuming.

\section{INIRODUCTION}

Gait analysis forms an important part of the assessment of ambulatory stroke patients throughout the world. The majority of physiotherapists assess gait by observation due to the cost of gait analysis equipment and the space needed to store it. If well documented, observational analysis can give a good basis from which to judge improvement in the patient's condition but objective data for research cannot be obtained in this way. As it is becoming increasingly important to prove that physiotherapy treatment is effective, a study was undertaken to investigate the use of a simple but inexpensive method of collecting objective measurements.

\section{CORRESPONDENCE:}

M Riley

Physiotherapy Department

South Rand Hospital

Private Bag x 1

Rosettenville

2130

South Africa

\section{METHOD}

\section{Subjects}

Ten hemiparetic subjects were selected from the wards, clinics and physiotherapy department of the Johannesburg Hospital, these being the first ten patients who met the inclusion criteria. There were seven female patients and three male patients. Ages ranged from 21 to 73 years (mean 48.5 years). Eight of the patients had suffered a stroke. Seven of these were Middle Cerebral Artery Strokes and one was an Internal Carotid Artery occlusion with resultant blindness in the ipsilateral eye and hemiparesis, consisting mainly of very poor proprioception, on the contralateral side. Two of the patients had hemiparesis resulting from head injury. Bilateral neurological signs were not significant in these two patients, consisting of only a positive Babinsky sign on the non-hemiparetic side. Six of the patients showed an increase in muscle tone on the hemiparetic side. Three patients showed a decrease in muscle tone and the one patient with poor proprioception had normal muscle tone. One of the patients with significantly increased muscle tone was taking Lioresal and also wore an ankle-foot orthosis and ankle supporting boots.

Five of the subjects had a right hemiparesis and five had a left hemiparesis. Nine of them were right dominant and one left dominant. Onset of hemiparesis ranged from 3 months to 2 years prior to testing (mean 10.1 months).

\section{INCLUSION CRITERIA}

- To understand what was required during testing

- The ability to walk at least ten metres three times consecutively using any type of walking aid (except parallel bars) and requiring assistance from no more than one person.

\section{DATA COLLECTION}

- Each patient was allowed to read (or had read to him) an explanation of the project and was asked if he understood what was to take place and whether he was happy to take part in the trial.

- Each patient was rated according to the Massachusetts Functional Ambulation Classification (Appendix 1). 
- Ink pads were attached to the patients' shoes, red on the right and blue on the left. The ink pads were attached to the same point on each shoe along a central line drawn from toe to heel. A triangular pad was attached at the toe and a square pad at the heel. The triangular pads measured $2 \mathrm{~cm}$ at the base and $1 \mathrm{~cm}$ in height, the square pads measured $2 \mathrm{~cm}$ by $2 \mathrm{~cm}$. Each patient was then asked to walk at his most comfortable speed along a paper walkway placed over a measured fourteen metre length of corridor leaving ink footprints from which measurements were later taken.

- Measurements were taken over the central ten metres of the fourteen metre walkway with the first two metres being allowed for acceleration and the last two metres for deceleration. Data from seven temporal distance measurements were collected. The measurements started with the first heel strike over the starting line and ended with the first heel strike over the finishing line.

\section{DATA ANALYSIS}

Velocity or speed of walking - was measured in metres per second and was calculated by dividing the ten metre data collection section by the time taken in seconds to walk along it.

Cadence - steps per minute - was calculated by counting the number of steps taken over the ten metre data collection section, dividing by the time taken in seconds to walk along this section and then multiplying by 60 to bring this to steps per minute.

Step length is the distance from the initial contact of one foot to the initial contact of the successive step of the opposite foot. Right step length and left step length were measured (fig 1).

Stride length is the distance from the initial contact of one foot to the next initial contact of the same foot. 1t, therefore, includes both stance and swing phases (fig 1).

Stride length to lower extremity length ratio (SL:LEL) is the stride length divided by the lower extremity length, the lower extremity length being measured from the superior border of the greater trochanter to the foor, bisecting the lateral malleolus.
Base width at heel is the width between the heel markers on each foot. Measurements were taken from the centre point of the heel squares to the edge of the walkway and the smaller distance was subtracted from the larger. Base width at toe was calculated in the same manner using the apices of the triangular pads as reference points for measurements.

Foot angle refers to the amount of toeout or toe-in of each foot.

\section{RESULTS}

Velocity (fig 2), cadence (fig 3), step length (fig 4), stride length (fig 5), and SL:LEL (fig 6), all showed excellent correlation with functional ambulation as rated by the Massachusetts Functional
Ambulation Classification, with velocity showing the greatest correlation.

The Spearmann Correlation coefficient was used to test the strength of the correlation. A value of less than 0,05 was considered significant. Foot angle and base width at heel and toe did not show correlation with functional ambulation and the results are therefore not included.

\section{DISCUSSION}

The measurements of velocity, cadence, step length, stride length and SL:LEL, which were all shown in this study to correlate with functional ambulation, have also been tested by Holden et al $(1984,1986)$ in studies with hemiparetic and multiple sclerosis patients, with similar results.
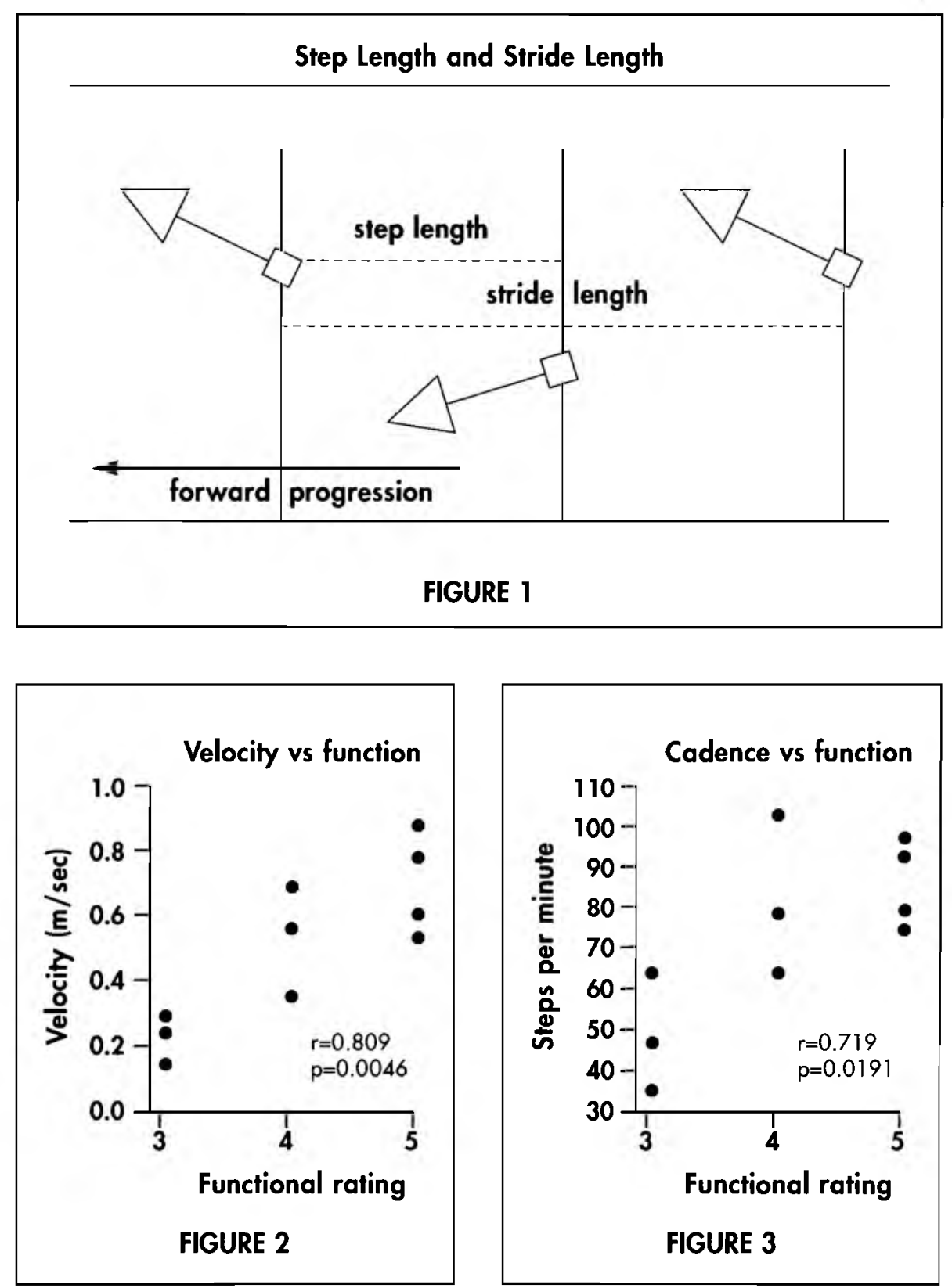


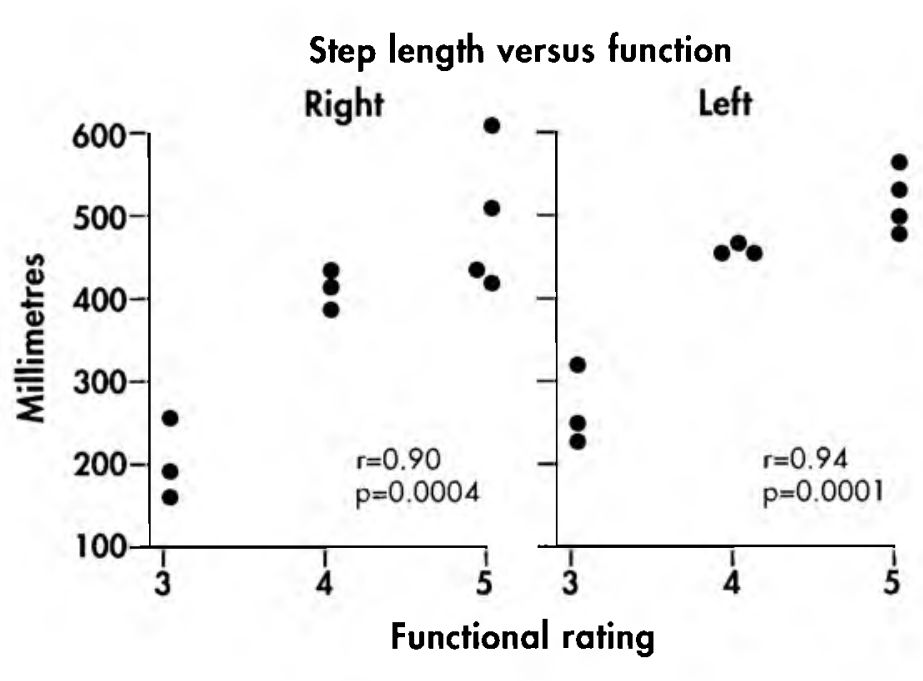

FIGURE 4

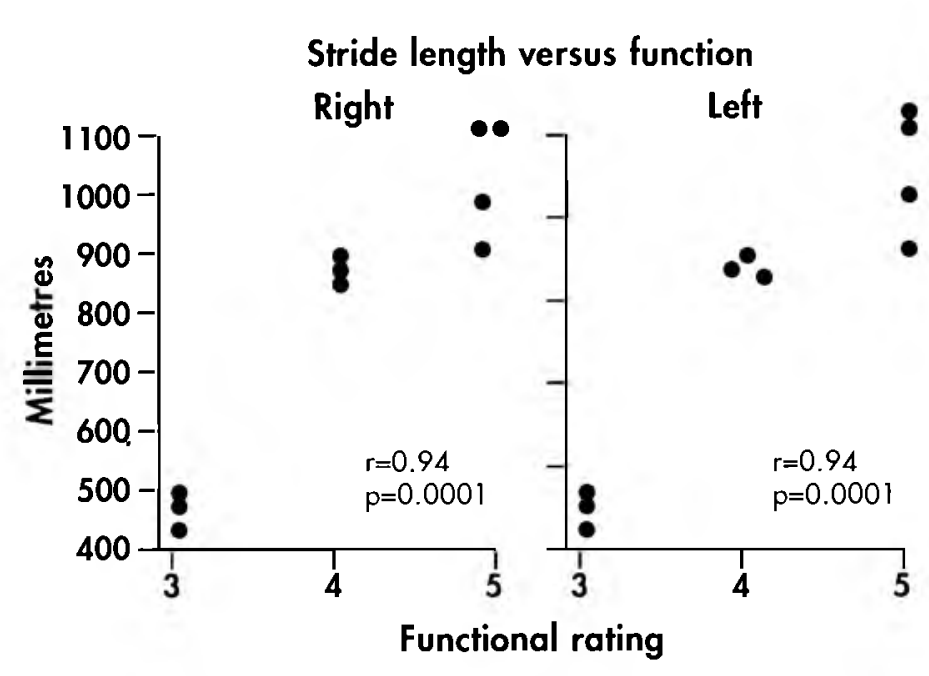

FIGURE 5

Stride length to lower extremity length (SL: LEL) versus function

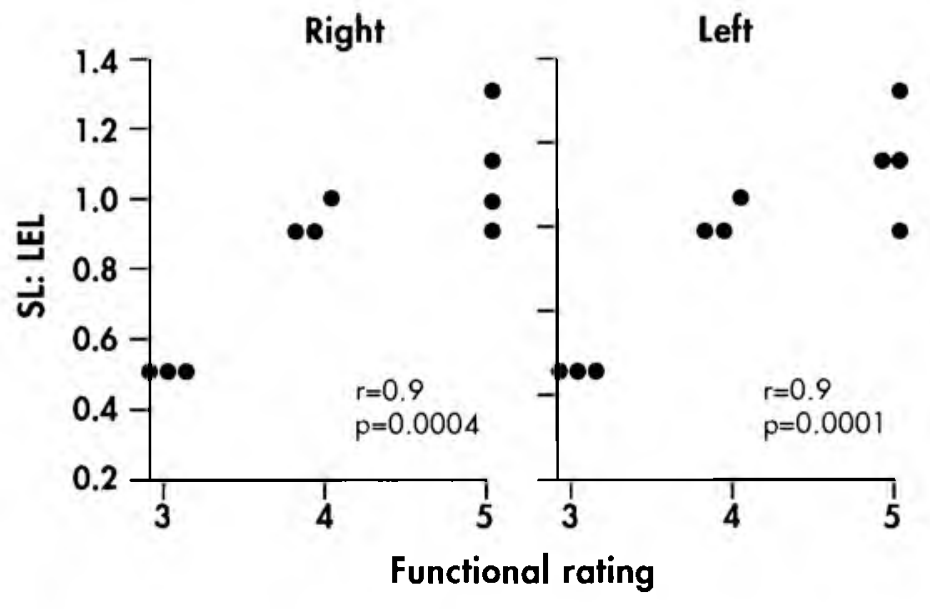

FIGURE 6
Velocity, which showed the greatest correlation to functional ambulation, has been described by Wade et al (1987) as being a reliable measurement and by Brandstater et al (1983) as being easily understandable and easy to use. It is also inexpensive to apply, requiring only a measured length of corridor or road and a stop watch. In fact velocity can be measured in almost any situation, from a physiotherapy department to any rural village or township in South Africa.

In normal walking right and left step lengths are equal and step length is usually speed dependent with an increase in step length occurring as velocity increases. As both right and left step lengths were measured in this study it was interesting to note that five of the subjects took a longer step with the affected limb while the other five did so with the unaffected limb. Four of the five right hemiparetic patients took a longer step with the unaffected limb and four of the five left hemiparetic patients took a longer step with the affected limb. All patients except one were right dominant. Lehmann et al (1987) discuss the fact that some gait parameters may be changed in hemiparetic patients due to slow walking speed while others may be due to faulty biomechanics. Further studies with greater numbers of patients are needed to determine whether right hemiparetic patients tend to take a longer step with the unaffected limb and left hemiparetic patients with the affected limb and whether dominance plays a part in step length after stroke.

The measurements of foot angle and base width at heel and toe, which were not found to correlate with function in this study, may be found to have greater significance in studies with a larger number of patients.

The velocity and cadence of the patient with poor proprioception, who had normal tone and good active movement, did not correlate so well with function as the other patients. Her problems of poor balance on uneven surfaces made her a category 4 patient on the functional ambulation classification but she showed a high velocity and cadence on level surfaces. She had in fact made an extremely good recovery on level surfaces having initially been unable to walk at all due to the proprioceptive loss.

The data collection method, using ink pads, presented certain initial difficulties. 
Moleskin, which has been used in other studies (Holden et al, 1984; 1986), was found to be insufficiently absorbent of the ink to provide clear footprints over the whole walkway. This problem was overcome by using orthopaedic felt dipped into the ink and then stuck onto the patients' shoes. The initial step or two were rather messy due to excess ink but this occurred in the two metre acceleration area and the footprints were clear as the patient stepped onto the measurement area and remained so to the end of the walkway.

The data analysis was extremely timeconsuming for each patient, as lines have to be drawn and measurements taken for each step along the ten metre walkway. It is however possible that a section of two strides in the centre of the walkway could give sufficiently reliable measurements to represent the whole walkway thus reducing analysis time.

\section{CONCLUSION}

The collection of objective measurements of gait using the ink footprint method is inexpensive and easy to use in any physiotherapy department. The data analysis is, however, time-consuming.

The measurements of velocity, cadence, step length, stride length and SL:LEL all correlate well with the Massachusetts Functional Ambulation Classification.

Velocity, which is the most significant measurement and also the easiest measurement to obtain should be recorded in all gait assessments.

\section{REFERENCES}

Brandstater ME, De Bruin H, Gowland C et al. Hemiplegic gait: analysis of temporal variables. Arch Phys Med Rehab 1983; 64:583-587.

Holden MK, Gill KM, Magliozzi MR et al. Clinical gait assessment in the neurologically impaired: reliability and meaningfulness: Phys Ther 1984; 64:35-40.

Holden MK, Gill KM, Magliozzi MR. Gait assessment for neurologically impaired patients: standards for outcome assessment: Phys Ther 1986; 55:1530-1539.

Lehmann JF, Condon SM, Price R, de Lateur BJ. Gait Abnormalities in Hemiplegia: their correction by ankle-foot orthosis. Arch Phys Med Rehab 1987: 68:763-771.

Wade DT, Wood VA, Heller A, Maggs J, Hewer RL. Walking after stroke. Measurement and recovery over the first 3 months. Scand Jnl of Rehab Med 1987; 19:25-30.

\begin{tabular}{|c|c|}
\hline \multicolumn{2}{|c|}{ MASSACHUSETTS FUNCTIONAL AMBULATION CLASSIFICATION } \\
\hline CATEGORY & DEFINITION \\
\hline 0. Nonfunctional Ambulation & $\begin{array}{l}\text { Patient cannot ambulate, ambulates in bars only, or requires } \\
\text { supervision or physical assistance from more than one person to } \\
\text { ambulate safely outside of parallel bars. }\end{array}$ \\
\hline $\begin{array}{l}\text { 1. Ambulator - Dependent for } \\
\text { Physical Assistance - Level II }\end{array}$ & $\begin{array}{l}\text { Patient requires manual contact of no more than one person during } \\
\text { ambulation on level surfaces to prevent falling. Manual contacts are } \\
\text { continuous and necessary to support body weight as well as } \\
\text { maintain balance and/or assist co-ordination. }\end{array}$ \\
\hline $\begin{array}{l}\text { 2. Ambulator - Dependent for } \\
\text { Physical Assistance - Level I }\end{array}$ & $\begin{array}{l}\text { Patient requires manual contact of no more than one person during } \\
\text { ambulation on level surfaces to prevent falling. Manual contact } \\
\text { consists of continuous or intermittent light touch to assist balance } \\
\text { or coordination. }\end{array}$ \\
\hline $\begin{array}{l}\text { 3. Ambulator - Dependent for } \\
\text { Supervision }\end{array}$ & $\begin{array}{l}\text { Patient can physically ambulate on level surfaces without manual } \\
\text { contact of another person but for safety requires standby guarding } \\
\text { of no more than one person because of poor judgement, } \\
\text { questionable cardiac status, or the need for verbal cuing to } \\
\text { complete the task. }\end{array}$ \\
\hline $\begin{array}{l}\text { 4. Ambulator - Independent Level } \\
\text { Surfaces only }\end{array}$ & $\begin{array}{l}\text { Patient can ambulate independently on level surfaces but requires } \\
\text { supervision or physical assistance to negotiate any of the following: } \\
\text { Stairs, inclines, or nonlevel surfaces. }\end{array}$ \\
\hline 5. Ambulator - Independent & $\begin{array}{l}\text { Patient can ambulate independently on non-level surfaces, } \\
\text { stairs and inclines. }\end{array}$ \\
\hline
\end{tabular}

